CURSO DE DIREITO ROMANO

João Arruda

I

\title{
Posição social da mulher na antiga Roma
}

Estudaremos a posição que a mulher ocupou em Roma, e como foi ela considerada na sociedade romana, segundo referem os escritores e particularmente os filólogos.

IHERING observa que grande foi a influência que exerceu a mulher no desenvolvimento do progresso do povo romano: diz que os romanos, nas suas lendas, se compraziam em ligar todos os grandes acontecimentos à intervenção de uma mulher. Cita Inering alguns fatos, que eu reproduzirei, embora sejam conhecidíssimos. Menciona, antes de tudo, as Sabinas, que conseguiram não só certas vantagens dos seus maridos romanos, mas tambem cujos nomes foram aproveitados para as diversas tribus que constituiam o povo romano. Há mais o fato de Lucrécia, e, segundo a lenda, ésta violação foi a gota de água que levou ao áuge a cólera romana, ou que fez transbordar a taça. Do mesmo modo, e como paralelo ao fato de Lucrécia, ha o atentado contra Virgínia. Os romanos suportaram os decênviros até que houvesse a violação de Virgínia, que determinou a destituição dos decênviros. Os romanos ligaram ainda á intervenção de uma mulher, Veturia, a salvação de Roma, quando ameaçada por Coriolano; ligaram á ambição da mulher de Licínius Stola o acesso dos plebeus ao poder consular; ligaram á mãe dos 
Gracchos a maior influência no desenvolvimento do espírito democrático em Roma; e finalmente, quanto á lei Oppia, dizem os historiadores que foi a sua abrogação devida, única e exclusivamente, ás mulheres romanas. Eis o que diz IHERING, e a opinião de IHERING hoje é geralmente aceita por todas as pessoas que se ocuparam com o estudo das antiguidades romanas.

A mulher romana está longe de ser a escrava como pa rece, á primeira vista, pela simples leitura das fontes ou das leis que compõem o Corpus Juris. A mulher romana, segundo a feliz expressão de Reinach, foi na antiguidade a única mulher socialmente emancipada, embora pelas leis romanas ela estivesse em tutela perpétua. Refere Plutarcho que Catão, falando da influência que as romanas exerceram na sociedade, dizia que os romanos eram senhores do mundo, mas que eram escravos das suas mulheres.

Assim, nós vemos que em Roma a posição da mulher, socialmente, é a antítese da posição da mulher juridicamente.

Vejamos, analiticamente, o que foi a mulher em Roma, - ésta senhora dos cidadãos romanos, segundo a expressão de Catão, referida por Plutarcho.

Antes de tudo, narram alguns escritores que, desde o tempo do rapto das Sabinas, conseguiram as mulheres romanas a isenção de qualquer trabalho servil, e, particularmente, não eram obrigadas, no serviço doméstico, aos trabalhos da cozinha e da moagem. Façamos o paralelo da mulher romana com a mulher grega: enquanto a romana, na deductio in domun mariti, levava consigo a roca e o fuso, porque ela só se dedicava aos trabalhos de fiar e aos trabalhos domésticos elevados, e não servis, - a mulher grega, quando ia para a casa do esposo, levava consigo um utensilio de cozinha, para mostrar que ela iria trabalhar em todos os serviços da casa, e, particularmente, no serviço da cozinha, que era julgado vil pela mulher romana. A obrigação das romanas era fiar e tecer no atrium, criar os filhos, e dirigir, na qualidade de senhora, todos os serviços domésticos. Não se conservavam, como as gregas, em um gymneceo, separadas da sociedade dos homens. Longe disso, a mulher 
romana gosava de grande liberdade: era tratada por todos com o título de domina; sentava-se á mesa com o seu marido, e só tinha a proibição de beber vinho, não que se pretendesse restringir a sua liberdade, mas pela razão naturalíssima, de que nada avilta e rebaixa tanto uma mulher quanto a bebida alcó́lica. Em $10^{\circ}$ de Março dava-se a festa das matronales, e, então, celebravam-se as virtudes das mães de famílias romanas. As mulheres romanas eram consultadas, não só para os interesses da família, para o casamento dos filhos, mas tambem para os interesses do Estado, e elas intervinham em atos importantes da vida social e da política. Assim, Sulpicia, sogra de Postumius, serviu de assessora ao seu genro num processo sobre as Bacanáis. Cícero dá notícia de um consêlho em que ele tomou parte, juntamente com alguns seus amigos, achando-se presentes tambem, não só a mãi de um desșes seus amigos, mas ainda Porcia, mulher do grande orador romano.

Esta era a posição da mulher na sociedade romana, e a sua influência na política.

Ao sair á rua, a mulher romana trazia a stola matronalis, veste severa, que a indicava como digna de respeito aos transeuntes. Davam-lhe todos passagem. Não a podiam tocar, ainda quando era citada para vir a juizo. Em Roma se fazia a condução a juizo obtorto collo, e o sentido desta frase encontram-no no terceiro volume de Ortolan. A mulher, porém,não podia ser conduzida oborto collo, e não podia mesmo ser tocada de leve para ser chamada a juizo.

Mas, além disso, a mulher tinha diversas atribuições, diversos poderes, díversos direitos e várias faculdades na sociedade romana: intervinha em todos os cerimoniais religiosos, e é digno de nota que, justamente nestas festas religiosas, foi que se acentuou a desmoralização de Roma, particularmente na celebração dos mistérios da Boa Deusa. Tomavam parte em todos os banquetes solenes, nos espetáculos públicos, e podiam mesmo aparecer em juizo como advogadas, até o tempo em que, dando Afrania ou Cafarnia um grande escând ๆlo no Forum Romano, foi cassada ás mulheres essa faculdade. Mais tarde, porém, continuaram ainda 
com o direito de comparecer em juizo para defenderem os seus parentes, ou para prestarem o seu testemunho.

Quando morta, era a mater-familias conduzida ao Forum, e tinha a laudatio, isto é, um dos seus parentes ou um orador oficial subia á tribuna pública, e fazia o elogio funebre da finada. Eis os direitos, os poderes que tinha a mulher na sociedade romana.

Segundo Mommsen, o carater da mulher romana resumese numa palavra: austeritas, "a austeridade". Ela era a pureza sem mácula, mas arrogante, soberba e faustosa. Faltava-lhe a graça e a amavel serenidade da mulher grega.

Discutiam os escritores romanos se era pior a mulher que tinha a nobreza do sangue, se a que tinha a nobreza do dinheiro; e Catão dizia que a pior era a mulher rica. Escreveu tambem Juvenal "Intolerabilius nihil est quam femina dives". Mais tarde, quando se desenvolveu o fausto em Roma, as mulheres exigiam vestes luxuosas, púrpuras, ouro, pérolas, logo que éstas foram conhecidas em Roma, carros dourados, etc. A lei Oppia, que se opunha ao luxo das mulheres, não poude impedir que elas fossem sempre conduzidas no carpentum e noutros veículos dourados e do maior preço.

Até á segunda guerra Púnica houve em geral pureza nos costumes femininos em Roma. SÉnECA, referindo-se a esse tempo, diz: "soeculum quo impudicitia monstrum erat, non vitium". Foi justamente na segunda guerra Púnica que o luxo, a falta de religião e o desenvolvimento da riqueza, levaram as mulheres romanas á dissolução, tornada proverbial na história da humanidade. Enfim, a guerra civil acabou, segundo Mommsen, o que haviam começado estes fatores da dissolução romana. E' necessário, porém, que nós reconheçamos que Mommsen, não deu todos os fatores: do despejo e da dissolução da mulher romana: outros fatores houve, além do luxo, da falta de religião e da riqueza, fatores que, por brevidade, eu calarei nesta prelecção.

E' digno de menção, pois isto influe na direção que nós: devemos dar ao regimen dos bens no matrimônio, que, em Roma, a separação de bens do casal produziu sempre os 
maiores danos na moralidade da familia. A mulher, que tinha a administração de seus bens separados, tinha sempre para os reger um procurador, que era seu conselheiro, seu confidente e, frequentemente, seu amante. E' esse indivíduo, que, pelos escritores da época, foi denominado "speciosus procurator, calamistratus procurator, formosus assecula". Nada pior, diziam os escritores da época, do que uma mulher rica: desde que um homem se casava com uma mulher que tinha fortuna, e que se sujeitava ao regimen da separação de bens, ele tinha alienado a sua liberdade e perdido a sua honra: "argentum accepi, dote imperium vendidi".

Estas considerações são da mais alta importância, porque entre os legisladores modernos discute-se sobre qual a fórma mais vantajosa de regimen matrimonial, se a da comunhão de bens, se a da separação.

Houve ainda, para aumentar a corrupção de Roma, a influência dos gregos. As mulheres romanas receberam da Grécia, a poesia, a filosofia, o culto das bacanais, os piores cultos gregos e a literatura mais deletéria da parte corrupta da Grécia; o que havia de bom na Grécia, não foi aceito pelas romanas; elas não adotaram os costumes das mãis de família honradas da Grécia: aceitaram o que vinha de meretrizes, o que vinha dos homens perdidos. E' digno de consideração isto, porque prova que, em geral, os povos têm tendencia para receber do extrangeiro, não o que o extrangeiro tem de bom, mas justamente o que o extrangeiro tem de máu.

Em Roma, cita-se como tipo da mulher depravada, pela influência da Grécia, Semprônia, que apareceu descrita com elegância e vigor por SALÚstio, na Conjuração de Catilina. Acredito que, nos seus estudos de latim, os srs. hão de ter visto o esboço do tipo dessa mulher inteligente e perigosa, feito por um dos maiores mestres do estílo, na antiguidade, qual foi Salústio.

Eis, em traços gerais, os motivos pelos quais se deu a corrupção da mulher romana. Mas, houve ainda, no tempo do Império, outras influências, que acentuaram essa corrupção. Usando da liberdade que eu acabei de descrever, as 
mulheres frequentavam o teatro, o anfiteatro e o circo; aí travavam relaçôes com gente das piores classes de Roma: tinham ocasião de se aproximar dos atores e dos homens mais pervertidos daquela dissoluta sociedade. Finalmente, gosavam das representações lúbricas do teatro e das sanguinolentas cenas de carnificina do circo. Ora, é impossivel que a obcenidade e a luxúria, no teatro, e a ferocidade do circo, não exercessem uma ação, uma influência profundamente danosa sobre o espírito da mulher romana. Além disso, havia a instituição da escravidão, uma das chagas mais horrorosas dos povos civilizados. A escrava não pode resistir ao senhor. Nesse sentido, ha a mais bela composição oratória que conheço no genero, qual foi a homilia de Massılıon, deante de um rei de França, mostrando quão facil era ao rei dar pasto aos seus vícios, quão grandes eram as tentações a que estavam sujeitos os poderosos da terra, que não encontram resistência aos seus desejos. Era exatamente o que se dava em Roma. Estabelecido o pelicatus, desde a mais remota antiguidade romana, facilitado o adultério do marido, pela escravidão, pela circunstância de não poder a escrava resistir ao senhor, sendo a mulher romana austera, severa, aspera, grave, e merecendo mais respeito do que amor ao seu marido, havia este de procurar o prazer fóra do domicílio conjugal, e, daí o começo da corrupção da família, por parte do homem.

Assim, nós vemos que, nos primeiros tempos de Roma, ainda os cônjuges não se separavam, retidos pela religião e pela opinião pública. Mais tarde, no quinto século, começaram os envenenamentos. Houve, segundo dizem os historiadores, uma verdadeira epidemia de envenenamentos de maridos; e atribuem isto á circunstância de ser o casamento nobre, o casamento pela confarreatio, uma união indissoluvel. Não é isso fóra de contestação. Baseia-se em uma narrativa de Dionisio de HaLicarnasso, que afirmou que a diffiareatio só se fazia quando um dos cônjuges era condenado á morte.

Se é verdadeira essa doutrina, baseada no referido trecho de Droniso, é facil de compreender porque as mulheres, 
não tendo o recurso do divórcio, e acorrentadas na família pela opinião pública, recorriam ao envenenamento do marido: era que, nessa época, já começavam a afrouxar-se os laços da família, diminuido o sentimento religioso das mulheres, e aumentados os abusos dos maridos. Já a domina não tinha a resignação precisa para sustentar o heróico papel da austera mater framilias.

Parece que a explicação é satisfatória, e que essa epidemia de envenenamentos não se daria, se tivesse havido a instituição do divórcio, que nós poderiamos chamar, pitorescamente, uma válcula de segurança naquela sociedade que foi gradualmente se pervertendo, até ser, na sua última fase, mais do que corrupta.

\section{Solenidades do casamento na antiga Roma}

Passarei a tratar de uma materia de que se ocupa PoTHIER no apêndice ao L. 23, T. 2, de suas Pandectas. Refiro-me ás formalidades, ou antes, ás festividades que se faziam por ocasião do casamento romano, parecendo-me que é de vantagem conhecerem os srs. ésta matéria, afim de não darem uma má inteligencia á afirmação que fiz, acompanhando diversos romanistas, que sustentam que os casamentos, em Roma, se ultimavam sómente pelo consentimento das partes. PotHier trata do assunto com grande erudição,e, embora se refira tal estudo mais á filologia do que ao Direito propriamente, julgo que é materia de utilidade, e que não será enfadonho para os srs. conhecer este cerimonial das núpcias.

Segundo Mommsen, estes ritos nupciais comuns ligamse todos á forma mais antiga, á confarreatio, cujo carater 
distintivo se achava, não nos sacrifícios ou nos ritos religiosos, mas no concurso dos ministros do culto oficial. Assim, nós temos de notar que os romanos, supersticiosos como eram, entendiam que havia dias e tempos impróprios para a celebração dos casamentos. Ainda ha vestígios dessas crenças romanas, atualmente, nas épocas que a igreja romana considera como impróprias para serem celebrados casamentos, embora para isso sejam dados outros motivos, que não o de serem épocas infelizes ou nefastas. Em Roma não se podiam efetuar casamentos em diversas épocas, principalmente com virgens, porque os romanos consideravam o casamento como uma violência, e, portanto, como uma profanação, casar-se alguem com uma virgem em dias feriados.

Além disso, havia o impedimento de casamento nas vésperas de dias atri, porque era no dia imediato ao casamento que a mulher entrava a fazer os sacrifícios familiares; que entrava nas práticas religiosas; e, como nesses dias atri, não se podiam realizar atos religiosos, ficava ela privada de satisfazer essas cerimônias.

Havia ainda a proibição durante o tempo dos parentais que eram em fevereiro, e que se julgava tambem nefasto para a celebração de núpcias, segundo refere Ovidio nos seus "Fastos", L. 2." "Mense malas Majo nubere vulgus ait". Eis as épocas durante as quaes os supersticiosos não se casavam.

Consideravam os dias de Julho como época feliz para a celebração dos consórcios. Tomados os auspícios, deliberava-se a celebração do casamento. A esposa era penteada com seis tranças (señi crines), e vestida de uma túnica branca reta, isto é, cujos fios eram verticais, á antiga, tendo na véspera deixado a toga proetexta. Sobre a cabeça trazia uma corôa, e era velada pelo flammeum, ou véu amarelo escuro quasi vermelho. Os cabelos eram metidos numa côifa amarela (reticulum luteum). Havia ainda uma circunstância importante, que é referida por IhERING, - a da passagem de uma lança sobre a cabeleira da nôiva, e, segundo referem outros, ésta era penteada com a ponta de um dardo. que tivesse sido cravado no corpo de um homem que tives- 
se morrido no circo, de um gladiador (hasta coelibaris). IHERING liga importância a isto, e, com ef eito, parece que ésta lança era o símbolo do poder ou da fôrça, do domínio do marido sobre a mulher. Os romanos tambem davam outra interpretação, dizendo que tambem simbolizava a união do homem e da mulher. Mommsen diz que os romanos, nos últimos tempos, não mais conheciam a significação deste símbolo.

Além disso, trazia a nôiva consigo uma corôa ou grinalda (corola) de verbena, que, segundo Reinach, era posta sobre sua cabeça, e, segundo Pothier, oculta sob o manto. Era tambem necessario que ela trouxesse consigo os objetos domésticos: a roca e o fuso. Eis como a nôiva seguia para a casa do marido. E, aqui, eu lembro aos srs. o nome da cerimônia de que tanto lhes tenho falado; "a deductio in domum mariti", sob os auspícios de Juno Domiduca.

A nôiva era conduzida por jovens impúbres vestidos de túnica proetextio. Um deles levava nas mãos um facho de madeira de espinheiro branco (spina alba), que era tida como feliz ou de bom agouro; dois outros impúberes conduziam a nôiva pelas mãos; finalmente, um rapaz ingênuo, que os romanos denominavam Camillo, conduzia os objetos domésticos, pertencentes á nôiva, num cesto (cumerum). Eis como se formava o cortêjo ou o séquito da nôiva, que saía de casa de seus pais para a de seu marido. A circunstância que lhes mencionei do facho de espinheiro branco mais uma vez confirma a superstição dos romanos.

Chegada a nôiva á porta, que se achava ornada de folhagens, era inquirida sobre seu nome, respondendo ela que se chamava Gaia. Os autores não estão de acôrdo quanto á significação desta resposta; mas, geralmente, acredita-se que Gaia tenha sido uma excelente dona de casa, da qual as outras mulheres tomavam o tipo e tambem o nome. Daí, naturalmente, vem a célebre fórmula que os srs. já devem ter ouvido certamente: "Quando tu Gaius, ego Gaia, ou "Ubi Gaius, ibi Gaia". Era, em seguida, segundo Mommsen, que se davam as cenimônias da dextrarum junctio, e, em caso de confarreatio, da oferenda incruenta (painis farreus). Antes 
de atravessar a porta, a esposa ungia com óleos os seus humbrais, e a ornava de tiras de lã. Daí vem derivar-se uxor de unxor. Tem ésta palavra muitas derivações, todas porém, inaceitaveis, segundo Miguel BrÉal, no seu "Diccionario Etimológico".

Quando a nôiva tinha de penetrar na porta, não podia pisar na soleira: saltava-a, ou era carregada pelas companheiras. Dão tambem deste contume diversas explicações, sendo uma delas que os romanos queriam rememorar o "rapto das sabinas". Havia um outro processo de entrar na casa: rompia-se uma parte do muro para que a esposa penetrasse por esse vão. Desde que se achasse dentro da casa, ela recebia as chaves das mãos do marido, sentando-se depois em um banco onde havia a pelle de um animal que tivesse sido sacrificado, e recebendo ainda das mãos do marido a agua colhida por um menino feliz e o fogo, que vinha em uma madeira de qualidade feliz, ou que os romanos consideravam de bom agouro. 0 festim era iluminado por cinco fachos, tomando parte nele os convidados. Nestas cêias que se chamavam epuloe geniales, segundo referem vários historiadores, podia-se despender o dôbro do que se gastava em qualquer outra cêia, segundo as leis suntuarias. Faço esta observação para dar aos srs. uma noção do que eram as leis suntuarias, cujo restabelecimento tem sido pedido modernamente. Durante o banquete gritavam os convivas: Talassio! não havendo uma exata explicação desse vocabulo. Entretanto, asseveram alguns que era o nome de um chefe na ocasião do rapto das sabinas, e outros que ésta palavra era composta das palavras Talma Lasa, que significavam - Juno Rainha.

Durante o banquete, o esposo lançava grande porção de nozes, que eram apanhadas pelos rapazes. Desta cerimônia ou deste costume os escritores dão diversas explicações, que, por brevidade, eu omitirei. Os rapazes impúbres tiravam as suas túnicas proetextas, e começavam a fazer discursos e a cantar versos, que eram denominados fescenninos (locutio fiescennina). Eis como se desenvolvia o banquete nupcial. 
Em seguida era a esposa conduzida ao quarto onde estava preparado o leito nupcial. Os convidados acompanhavam a esposa até ao quarto nupcial, sendo ela seguida pelas pronuboe, dando-se nessa ocasião a cerimonia do arrancamento da tocha, que ainda se conserva até hoje na Itália em certas festividades. Sentava-se a esposa por algum tempo num banco dedicado ao deus Priapo, e depois era conduzida para o leito pelas pronuboe, mulheres de provada castidade, e que não se houvessem casado por mais de uma vez. Era então que se dava a cerimonia de desatar do cingulum herculeanum nodo vintum. Hercules era o gênio da fecundidade, pois, segundo referem escritores, teve setenta filhos.

No dia imediato, havia o banquete denominado repotio. A esposa entrava a fazer os sacrifícios domesticos aos deuses lares; recebia os presentes das amigas.

E' de notar, observa Pothier, que nos casamentos que não fossem celebrados pela confarreatio deva-se um rapto simulado da nôiva. Diversos amigos do nôivo iam á casa da mãi da nôiva ou da matrona que para ela se achasse nessa posição, e, armados de espadas desembainhadas, como si fossem prontos para um ataque, arrebatavam a nôiva. Era uma cerimônia simbólica em memória do rapto das sa* binas.

Eis o que ha a respeito das cerimônias ou fórmulas do casamento romano, e, nesta exposição, eu acompanhei, principalmente, dois escritores que merecem grande confiança, a saber: Pothier e Reinach, sendo este último um dos mais notaveis filólogos dos tempos modernos. 